$\mathrm{V} \Delta \mathrm{K} 352 / 353$

ББК 66.3(0),124

DOI 10.22394/1682-2358-2020-1-19-27

O.S. Skorokbodova, Candidate of Sciences (Politics), Docent of the Political Science Department, Povolzhsky Institute of Management named after P.A. Stolypin, Branch of the Russian Presidential Academy of National Economy and Public Administration

\section{FORMATION \\ OF LOCAL ELITES \\ OF SETTLEMENT LEVEL IN SARATOV REGION}

Analysis of the qualitative composition of the local elite of the settlement level in municipal districts of the Saratov region is presented. As a result of the study it was revealed that at the settlement level informal practices of elite formation are decisive, the basis of the qualitative composition are employees of the public sector and representatives of medium and small businesses. The greatest powers at the settlement level are vested in the heads of executive authorities embedded in the regional power vertical.

Key words and word-combinations: local self-government, settlement level, local elites.
О.С. Скороходова, кандидат похитических наук, дочент кафедри политических наук Поволжского института управления имени П.А. Стольпина - филиала Российской академии народного хозяйства и государственной службь nри Президенте РФ (email: olsko@yandex.ru)

\section{ФОРМИРОВАНИЕ МОКААЬНЫХ ЭАИТ ПОСЕАЕНЧЕСКОГО УРОВНЯ В САРАТОВСКОЙ ОБ $\Lambda$ АСТИ*}

Аннотация. Представлен анализ качественного состава локальных элит поселенческого уровня муниципальных районов Саратовской области. Выявлено, что на поселенческом уровне неформальные практики элитообразования являются определяющими. Доказывается, что наибольшими полномочиями на поселенческом уровне обладают главы исполнительных органов власти, встроенные в региональную властную вертикаль.

Ключевые слова и словосочетания: местное самоуправление, поселенческий уровень, локальные элиты.

И сследование региональных политических элит в современной России актуацизировалось с началом развития политической регионалистики в целом [1]. С одной

* Статья подготовлена при финансовой поддержке Российского фонда фундаментальных исследований, проект № 1703-00566 «Поселенческий уровень местного самоуправления в России: политическое положение и проблемы развития». 
стороны, научно-пубцикационная активность по этому направлению явцяется одной из наиболее явных, с Аругой стороны, на наш взгляА, наблюдается некое «охлаждение» исследовательского интереса к Аанной проблематике за последние годы в связи со снижением степени политического влияния региональных мидеров по сравнению с периодом конца 1990-х годов. Можно вести речь о смещении фокуса анализа с вопросов теоретико-методологического порядка на более узкую проблематику. Основные модели, закономерности рекрутирования региональных и мокальных политических элит изучались в работах А.Г. Сельцера, И.А. Ветренко, И.К. Жукова [2; 3] , в которых осуществлен анамиз опыта управления на уровне административных центров и малых городов в составе отдельных субъектов Федераџии. ОАнако, по мнению А.Е. Чириковой, «фундаментальной теории регионацьных элит в России не выработано» [4] .

Еще менее изученными и, казалось, не имеющими исследовательского интереса явцяются мокацьные политические элиты муниципацьных поселений. РяА авторов считают некорректным относить акторов политического проџесса на этом уровне к элите, так как первичное ознакомление с ситуацией выставмяет их в не самом выгодном свете с позиџии их эмитарности.

Прежде всего следует понять, можно ми однозначно идентифиџировать властную элиту муниципального уровня как политическую. Помимо опредеменных законом прав и полномочий, наличия собственного аппарата работников, политическая составляющая предполагает подготовку и реализацию стратегически важных в политике решений, а также наличие у носителей властных функций определенных ценностей и установок, определяющих их особый образ жизни и поведения [4, с. 53] .

Аогика анациза процесса элитообразования таким образом традиционно выстраивается в рамках формально-институционального подхода, предполагающего селективные и элективные механизмы, и ресурсно-акторного подхода, позволяющего выявить наиболее значимых участников политических отношений на местах, Аействительно влияющих на условия принятия решений. В этом контексте рекрутирование элит трактуется как «выходная функция политической системы, выражающаяся в формировании групп политического руководства и принятия решений» [5]. Это означает, что управленческая мотивация формируется исходя из особенностей системы, типа регионацьного политического режима. В регионах с гомогенной политической эмитой, возглавцяемой главой субъекта Федераџии, складывается исключительно корпоративный вариант кооптации в «свои ряды». Наличие же гетерогенности в элитных группах, отсутствие главного медиатора этих отношений предполагает конкурентное начало в борьбе за власть, следовательно, большее разнообразие механизмов и каналов обновления «класса управцяющих».

В России, особенно на цокацьном уровне, важное место занимает кцановый принцип формирования эмиты, Аля которого характерны патрон-кциентские связи, отношения мичной преданности, корпоративная ориентация, значительная закрытость [6]. Ввиду территориальной ограниченности пространства корпоративная близость формируется за счет отношений землячества, родственных связей, системы знакомств в профессиональной сфере, взаимо- 
действия по Аинии «ОАноклассников» и т.п. В результате ядро региональной эмитной группы может иметь свою систему џенностей, самосознания, набор внешних атрибутов. Это обусловливает корпоративную замкнутость, неАопущение попадания «чужих» в свои ряды. В какой степени данные тенденции характерны для самого мокального уровня реализации политики, преАстоит выяснить в рамках Аанной публикаџии.

Исследователям региональных элит свойственно повышенное внимание к проблеме функционировании вертикали власти в современной России. Это, несомненно, обусловливает зависимое положение власти субъектов Федерации от решений и позиџии федерального центра, что делает региональную элиту менее привлекательной с исследовательской точки зрения. Именно поэтому поселенческий уровень представляется еще менее интересным, так как по могике он подотчетен районным вмастям, которые, в свою очередь, также не самостоятельны и выполняют указания региональных властей. ОАнако не стоит упускать из внимания один немаловажный факт: поселенческий уровень, за реАким исключением, в отличие от регионального уровня, напрямую не попадает в фокус внимания федеральной власти, что освобождает местные элиты от жестких федеральных рамок и дает им относительную возможность Аля «маневра» в своем поселении. Занятым исполнением федеральной повестки региональным элитам также не всегда удается выстроить сильную вертикаль вмасти по принципу "регион - районы - поселения». Исходя из этого, можно преАположить, что поселенческие элиты, в отличие от региональных, имеют некоторый потенциал относительно независимых политических акторов на своем уровне политического проџесса. Следовательно, исследования в этом направлении крайне актуальны. Это касается механизмов рекрутирования элит на поселенческом уровне, процессов внутри элит и образуемых ими структур, управления ресурсами, влияния во внутренней и внешней среде.

Современное состояние системы местного самоуправления в России преАполагает почти полную зависимость в иерархии власти с позиџий и политической, и экономической самостоятельности, за некоторым исключением крупных муниципальных образований городского типа. В настоящее время одним из немногих реальных механизмов влияния на региональный политический проџесс можно считать практику «муниџипального фильтра» при выАвижении кандидатов на выборы высшего должностного миџа субъекта Федерации. С этой точки зрения цемесообразным целесообразным преАставляется качественный и количественный анализ партийной, профессиональной принаАлежности депутатов муниџипального уровня, а также оџенка мотиваџии их поведения в региональном политическом процессе и вероятные перспективы вхождения в состав региональной элиты.

Выстраивая могику структурирования муниципального «высшего кмасса», необходимо придерживаться традиџионного подхода, предполагаюшего вкАючение в фокус исследования властной элиты (исполнительной и представительной) и неформальных (экономических, общественных, этноконфессиональных) мидеров. В ходе исследования был проанализирован качественный состав местной элиты семнадџати муниципальных образований Энгельсского и 
Екатериновского муниципальных районов Саратовской области. Выбор данных территорий обусловлен обычной Аихотомией: один из наиболее экономически состоятельных муниципальных районов региона (домя дотаций из бюАжетов Аругих уровней менее 5\%) - один из множества дотационных муниџипальных районов Саратовской области (Аоля Аотаџий от 20 до 50\%) [7].

Екатериновский муниципальный район Саратовской области образуют Авенадцать муниципальных образований - одно городское поселение (поселок городского типа Екатериновка) и одиннадцать сельских поселений. Особенности политического устройства, а также основных акторов влияния в поселке городского типа Екатериновка, который явмяется центром одноименного Екатериновского района и входит в его состав в качестве муниципального образования, подробно исследованы в нашей работе ранее [8]. Например, в соответствии с Уставом Екатериновского муниципального образования его глава избирается из числа депутатов Совета сроком на пять мет и полностью подконтролен представительному органу и населению, что по классическим моделям местного самоуправления соответствует схеме «сильный совет - слабый мәр». ОАнако Совет, по сути, никак не опредемяет мокамьный политический проџесс, что вписывается в общероссийскую тенденџию низкой степени влияния преАставительной власти на принятие политических решений и ее подчиненного положения по отношению к власти исполнительной. По результатам электоральной кампании 2018 г. произошла смена главы администрации поселка, и действующий глава А.В. Мокров стал депутатом-инкумбентом местного Совета. Его предшественник на посту В.В. Кочетков принимац участие в кампании, но не переизбрался.

Статус административного центра означает, что в Екатериновке проводятся ключевые мероприятия местной политической жизни, по факту отождествляемые с политикой в районе в целом. В Екатериновке располагаются органы власти районного уровня, основные объекты инфраструктуры (связь, почта, районная больница и т.А.), подразделения органов государственной власти (полиция, прокуратура, пенсионный фонА, ЗАГС), местные ячейки политических партий. Следовательно, наблюдается полная мимикрия внутримуниципальной власти поселка мокальному политическому режиму района. Несмотря на то что непосредственно на территории поселка городского типа Екатериновка функционируют важные Аля района и Саратовской области преАприятия (АО «Екатериновский Элеватор», ООО «Старый Элеватор», ООО «Екатериновская Мука» и др.), власть на поселенческом уровне не представлена аффилированными с ними мицами.

Соразмерными по количеству жителей и экономическим активам Екатериновскому муниџипальному образованию можно считать Бакурское (с. Бакуры), Индустриальное (п. Индустриальный) и Сластухинское (с. Сластуха) муниципальные образования. Как отмечают местные эксперты, в составах советов указанных муниџипальных образований, в отличие от административного џентра района, присутствуют наиболее значимые и известные на поселенческом уровне киџа - руководители образовательных учреждений, учителя, управленцы агропромышиенных преАприятий, а также представители

22 Bulletin of the Volga Region Institute of Administration • 2020. Vol. 20. № 1 
национальных меньшинств. Рекрутирование местной элиты в органы власти главным образом происходит в результате кичного волеизъявления, так как конкурентных выборов в рассматриваемых муниципальных образованиях не наблюдается. Районная власть ретранслирует мокальным элитам позицию региональных элит, но сама по себе не явцяется авторитетной дмя землевладельцев и крупных производитемей сельхозпродукции.

На территории Энгельсского муниципального района, который явмяется наиболее экономически состоятельным в составе Саратовской области, ведут экономическую деятельность и имеют производства крупные зарубежные компании - Bosch, Henkel и другие [9]. Энгельс, административный центр муниципального района, - второй по значимости гороА в регионе, поэтому крупное городское поселение и окружающие его мунищипальные образования представмяют интерес Аля политических элит. В составе района пять муниципальных образований - четыре сельских поселения и одно городское. Энгельс неформально именуют городом-спутником обцастного центра, что подтверждается частыми назначениями руководителей из областного правительства на ключевые Аолжности в мунищипальном образовании и наоборот. Так, прежнее руководство района и города в июне 2019 г. перешио в кабинеты Правительства Саратовской области, а экс-глава Энгельсского муниципального района А. Стрелюхин занял пост вище-губернатора региона, фактически став вторым человеком в иерархии администрации региона. В свою очередь, бывший министр строительства и ЖКХ области А. Тепин в июне 2019 г. назначен руководителем Энгельсского муниципального района. Подобный кадровый обмен межАу областным џентром и районом свидетельствует о том, что энгельсские элиты имеют все признаки региональных элит. По этой причине рассмотрение города Энгельса с точки зрения наличия в нем исключительно мокальных элит нецелесообразно.

В муниципальных образованиях Энгельсского района, сформированных сельскими поселениями, местные элиты действительно следует считать мокальными, так как часть их представителей обладают активами в посемениях и избираются в местные представительные органы дяя отстаивания прежде всего интересов своих бизнес-структур. Согласно экспертной информации, на территории Красноярского муниципального образования расположен целый ряд оздоровительно-развлекательных комплексов, а также загородные дома и дачи политической элиты Саратовской обцасти. Некоторые предприниматели из состава совета депутатов получают подряды на строительство различных объектов и ремонт инфраструктуры Аля максимально удобного передвижения по ней преАставителей региональных элит.

ОАнако эксперты из числа мокальной элиты муниципального образования (ввиду наличия руководящей должности в органах местной власти) отмечают, что на практике политической вмастью они не обцадают - все необходимо согласовывать с районными властями. Советы депутатов по большей части формируются из числа миџ, «одобренных» администрацией района. Финансы мунищипальных образований также находятся в ведении районных властей. «Муниципальный фильтр» во время выборов главы региона не позволяет местным депутатам проявить свою реальную волю. 
Таким образом, формальные мокальные элиты посеменческого уровня в Энгельсском муниџипальном районе не обладают реальной политической властью, находятся в жестких рамках, опредемяемых региональной элитой. Некоторые представители мокальной элиты, благодаря мичным связям с районной (а равно и с региональной) элитой, могут рассчитывать на размичные преференции в виде подрядов на строительство или обслуживание инфраструктуры на территориях муниџипальных образований. Но, как показывает практика, власти Энгельсского района и подконтрольные им цокальные эмиты не всегда обладают должными ресурсами и влиянием на местное население. Так, в феврале 2017 г. жкители села Аиповка Красноярского МО (бывшая колония немцев Поволжья Шефер) не позволили местным властям снять колокол с полуразрушенной кирхи [10]. Наџиональные меньшинства муниџипальных образований Энгельсского района заслуживают отдельного исследования по причине значительного превалирования неформальных практик в их среде. По сведениям экспертов, национальные сообщества сильны в Энгельсском районе - они контролируют значительную Аолю в строительном бизнесе, торговле и производстве.

Качественный состав региональной политической элиты чаще всего изучается в аспекте политико-биографического и соџиогенетического подходов [11]. Несомненным достоинством этих подходов можно считать относительную открытость биографических сведений о конкретном представителе «класса управляющих», возможность сравнить ключевые показатели в ретроспективном контексте, составить политико-психологические портреты преАставителей элитных групп. Конечно, соџиогенетический подход не Аает полностью объективного преАставления о реальных причинах и условиях вхождения человека «во власть», но в то же время позволяет сформировать исходную базу Аля анамиза неформальных политических практик и отношений внутри политической элиты [12]. С этой позиџии наиболее Аоступной базой можно считать общие биографические сведения о чиенах советов депутатов муниципальных образований, а также главах и их заместителях. Подобная информаџия о представителях бюрократического аппарата и неформальных значимых акторах мокамьного сообщества фактически закрыта. Анализ происхождения представителей органов исполнительной и представительной власти муниципального уровня и потенциальных каналов вхождения в органы власти позволяет оџенить и степень их «элитарности» относительно простого населения на поселенческом уровне.

На наш взгляА, особое значение имеют профимь высшего или среднего образования и профессиональная принадеежность представителей элиты в официальных органах власти, поскольку уровень местного самоуправления преАполагает решение предметных, имеющих конкретную практическую пользу вопросов организации благоустройства, жилищно-коммунального хозяйства, управления муниџипальной собственностью и землей, образования, зАравоохранения. Следовательно, можно делать выводы о степени компетентности руководящего состава сообразно этим задачам, а также о потенциальных каналах «вхождения во власть» в различных сферах профессиональной деятельности.

24 Bulletin of the Volga Region Institute of Administration • 2020. Vol. 20. № 1 
В ходе данного иссмедования было проанализировано 176 биографий депутатов местных советов, включая глав и их заместителей, поскольку они также имеют статус народных избранников, а также 23 сотрудника одной из муниципальных администраций. Высшее профессиональное образование имеют только 67 народных избранников (38\% от общего числа), как правило, это главы муниципальных образований и их заместители. Соответствуюшие данные у 81 депутата из общего числа отсутствуют. Остальные народные избранники имеют только среднее и средне-специальное образование. По профилю преобладающее большинство имеют педагогическую специализацию - 25 человек (30\%), 10 человек закончили сельскохозяйственные вузы, «технарей» - 9 человек, экономическое образование 7 человек, врачей и ветеринаров - 6 человек, юристов - 5 депутатов. Только два депутата из общего числа получили образование, связанное с государственным и муниципальным управлением. Таким образом, подавмяющее большинство составцяют «бюАжетники», наиболее Аисџиплинированные в управленческой системе вертикального типа. По сравнению с депутатами районного и областного уровней, почти на $100 \%$ имеющими высшее образование и даже научные степени, муниципалы посеменческого уровня серьезно уступают [13]. В органах исполнительной власти высшее образование имеет гораздо большее число сотрудников - 18 из 23, что можно объяснить, во-первых, более детальными законодательными требованиями к муниџипальным служащим по сравнению с народными пре Аставитемями, а во-вторых, наличием фиксированной заработной платы, в отличие от муниџипальных депутатов.

Наиболее важными в ракурсе Аанного анализа являются соџиально-профессиональные характеристики народных избранников, поскольку они отражают представительство интересов различных групп на уровне мунищипальной вмасти (табцица).

Соџиально-профессиональный состав преАставительных органов местного самоуправления

\begin{tabular}{l|c}
\hline \multicolumn{1}{c|}{ Социально-профессиональные группы } & Количество депутатов \\
\hline Бюджетники & $51(29 \%)$ \\
Представители бизнеса & $24(13,5 \%)$ \\
Фермеры (КФХ) & $20(11,3 \%)$ \\
Технические работники (инженеры, мастера) & $18(10,2 \%)$ \\
Индивидуальные предприниматели & $12(6,8 \%)$ \\
Менеджеры & $12(6,8 \%)$ \\
Муниципальные служащие & $12(6,8 \%)$ \\
Бухгалтеры & $8(4,5 \%)$ \\
Безработные, пенсионеры, водители & $11 \%$
\end{tabular}


По соџиально-профессиональному составу, как видно из табциџы, снова Аоминируют представители бюджетной сферы, но отметим, что преАставители бизнеса и частного предпринимательства, в том числе в сфере ведения сельского хозяйства, составцяют вторую крупную группу в депутатском корпусе (31,5\% по совокупности). БюАжетники, как правимо, моямьны действующему политическому курсу, контролируемы с позиџий использования административного ресурса, к тому же имеют «приличный» уровень образования и квалификаџии дмя работы в комлегиальных органах власти. Насколько можно считать системы образования, зАравоохранения, культуры потенциальными сферами дмя продвижения в политике? Несомненно, можно, поскольку достаточно обратиться к карьере сенатора от Саратовской обмасти $\Lambda$. Боковой - бывшего учитемя среАней школы. В депутатском корпусе областного уровня также работают преАставители бюАжетной сферы [13]. ОАнако всеобъемлющей, на наш взгляА, Аанную тенденџию считать нельзя. Гораздо более могичным с позиџий теории раџионального выбора явмяется стремление преАпринимателей участвовать в принятии решений на уровне ведения своего бизнеса. Муниципальный уровень управления предполагает установление правиц оформления собственности, земельных участков, установцения тарифов и местных налогов, то есть создание Аля себя максимально возможных условий дмя работы и развития. При этом можно отметить тенденцию демегирования (наряду с главами администраций) наиболее успешных и масштабных на этом уровне предприниматемей в районное Собрание депутатов. Таким образом, нацичие значимых на данном уровне экономических активов можно считать одним из ключевых условий вхождения в состав органов муниципальной вмасти.

Наиболее политизированным считается показатель партийной принадмежности депутатов и сотрудников местных администраций. В Саратовской обцасти оАнозначно сложицось преобладание «партии вцасти» в региональном, и, следовательно, муниципальном политическом проџессе. Из 176 депутатов 146 явцяются выдвиженцами от «ЕАиной России», есть пять представитемей партии $\Lambda \Lambda$ ПР, четыре коммуниста (КПРФ), один от «Справедливой России» и шестнаАџать кандидатов, избравшихся в состав Советов, - самовыдвиженцы. В составе администраџии одного из муниципальных образований из 23 сотрудников партийную принадлежность («ЕАиная Россия») имеют Аесять человек, то есть партийный ресурс можно считать оАним из основных и обязательных источников вхожАения в состав муниципальной элиты.

На основании глубинных интервью с работниками администраций посемений, анализа биографий местных депутатов и глав администраций, сбора и обработки информации о формальных и неформальных акторах политической, соџиальной и экономической жизни в муниџипальных образованиях двух районов Саратовской обцасти удалось прийти к следующим выводам:

- на поселенческом уровне не работают механизмы рекрутирования, закономерные дмя региональных и федеральных элит, хотя неформальные практики (Аичные связи) явмяются опредемяющими; 
- основная часть формальной поселенческой элиты состоит из работников бюджетной сферы и представителей среднего и малого бизнеса;

- наибольшими полномочиями на поселенческом уровне обладают главы исполнительных органов власти, так как они действуют в соответствии с прямыми указаниями вышестоящих инстанций;

- крупный бизнес, если таковой имеется в посемении, предпочитает демегировать своих представителей в районные или даже областные собрания депутатов, в которых, например, принимаются решения о формировании и расходовании бюджета.

Итак, опыт Саратовской области показывает, что преАставители мокальной политической элиты выступают как наименее влиятельные акторы регионального и даже муниципального политического процесса. Наличие формального статуса и атрибутов принадлежности к «классу управляющих» не являются определяющими с точки зрения влияния на принятие кАючевых политических решений. Отсутствие свободы деятельности, общих ценностей и установок у данной группы предопределяет крайне ограниченную возможкность проявления иниџиативы развития системы местного самоуправления в цемом.

\section{Библиографический список}

1. Гельман В.Я., Рыженков С.И. Политическая регионалистика в России: история и современное развитие. // Полис. 1999. № 3.

2. Сельиер Д.Г. Рекрутирование локальной административной элиты России: исходные данные для построения системно-динамической модели // PRONUNK. Современные политические процессы. 2017. № 2 (18). С. 27-32.

3. Ветренко И.А., Жуков И.К. Региональная политическая элита: основные тенденции в системе рекрутирования // ПОЛИТЭКС. 2013. Т. 9, № 3. С. 62-73.

4. Чирикова А.Е. Региональные элиты России. М., 2010.

5. Политическая наука: словарь-справочник / авт.-сост. И.И. Санжаревский. Тамбов, 2010.

6. Нигматуллина Т.A. Клиентелизм как политический тренд регионального элитообразования // Вестник БИСТ. 2017. № 3 (36). С. 7-16.

7. Названы самые зависимые от дотаций районы Саратовской области // Взгляд-инфо. 2019. 30 окт. URL: http://www.vzsar.ru/news/2019/10/30/nazvany-samye-zavisimye-ot-dotaciyrayony-saratovskoy-oblasti.html

8. Скороходова О.С. Политическое положение и развитие местного самоуправления в городских поселениях: опыт кейс-анализа // Политическая наука. 2019. С. 124-137.

9. Перечень крупных и средних предприятий обрабатывающих производств Энгельсского муниципального района URL: http://www.engels-city.ru/prompred

10. Жители Липовки пытаются отстоять столетний колокол на лютеранской кирхе. URL: http://www.vzsar.ru/news/2017/02/01/jiteli-lipovki-pytautsya-otstoyat-stoletnii-kolokol-na-luteranskoi-kirhe.html

11. Селезнева A.B. [и др.]. Российская политическая элита: анализ с точки зрения человеческого капитала // Полис. 2010. № 4. С. 96-106.

12. Семенов А., Шевиова И. Кто правит на местном уровне: сравнительный анализ корпуса глав муниципалитетов Пермского края и Республики Удмуртия // Региональная политика 2016: сборник статей и аналитических докладов / под ред. Д.И. Орлова. М., 2017. С. 259-271.

13. Семенова В.Г., Скороходова О.С. Качественный состав регионального парламента как показатель внутриэлитной интеграции и конкуренции: опыт Саратовской области // Вестник Поволжского института управления. 2017. Т. 17, № 4. С. 12-20. 